\title{
绿色化学课程思政教学模式探索与实践
}

\author{
叶美英 ${ }^{*}$ \\ 杭州师范大学材料与化学化工学院, 杭州 311121
}

\begin{abstract}
摘要: 在绿色化学课程中实施思政改革, 对提高学生的绿色化学意识和社会责任感都有重要的意义。本文介绍了教材 《绿色化学原理与应用》中不同章节教学内容的课程思政元素, 并提出了两种新的思政教学方法, 专题调查和讨论以及 开展社会实践。通过在教学过程中引入各项课程思政的内容, 获得了较好的教学效果。学生能主动将对绿色化学的学习 与当前的生态文明建设, 践行 “绿水青山就是金山银山” 联系起来, 增强了社会责任感, 对所学知识能为祖国的建设贡 献力量而倍感自信。
\end{abstract}

关键词: 绿色化学; 课程; 思政改革; 实践

中图分类号: G64; O6

\section{Practice of Course Ideology and Politics Education Mode in Green Chemistry Teaching}

\author{
Meiying Ye * \\ College of Material, Chemistry and Chemical Engineering, Hangzhou Normal University, Hangzhou 311121, China.
}

\begin{abstract}
Carrying out ideological and political education in green chemistry teaching can help students to improve their consciousness of greening of chemistry and sense of social responsibility. In this paper, several ideological and political elements according to different part of the text book Principle and Application of Green Chemistry were introduced, and two reform methods that were special reports of green enterprises or plastic recycling and developing social practice activities were put forth. These methods were proved to be effective and valuable when they were performed in the teaching process. The students can associate their green chemistry learning consciously with the ecological civilization construction in China and practicing the theory of "lucid waters and lush mountains are invaluable assets". They can be more confident and responsible to make a contribution to nation's development with their knowledge and skills.
\end{abstract}

Key Words: Green chemistry; Course; Ideological and political reform; Practice

育人之本, 在于立德铸魂。习近平总书记在全国高校思想政治工作会议和十九大报告中都对高 校的思想政治教育做出了重要指示。指出做好高校思想政治工作, 要因事而化、因时而进、因势而 新。要用好课堂教学这个主渠道, 思想政治理论课要坚持在改进中加强, 提升思想政治教育亲和力 和针对性，其他各门课都要使各类课程与思想政治理论课同向同行，形成协同效应。这为高校各基 础及专业课教师的教学改革指明了方向, 将思想政治教育、正确的价值观浸润到每一门课, 每一堂 课中, 提升思想政治教育的亲和力和针对性, 培养 “有理想、有本领、有担当” 的人才。 
党的十八大将生态文明建设纳入中国特色社会主义 “五位一体” 总体布局和 “四个全面” 战略 布局, 推动中国走绿色发展道路。“绿水青山就是金山银山” 这一科学论断正是树立生态文明观、 引领中国走向绿色发展之路的理论之基 ${ }^{[1]}$ 。从源头开始减少废物产生的绿色化学、清洁生产, 在化 学工业生产的各个阶段都严格遵循以环境保护为前提的原则, 则是在新文明观引领下的经济方式与 科技范式应该打开的方式。推进绿色发展首要解决的是人才需求数量不断扩充和人才需求质量不断 提高这一关键问题。绿色化学人才的培养, 对促进绿色化学化工的发展, 进而推动可持续绿色发展 起到了极大的作用。对绿色化学人才的培养, 不仅仅要培养他们拥有扎实的专业知识和实践能力, 更要让他们树立深刻的生态文明观和正确的价值观, 将实现当代人民和子孙后代的福利作为自身的 责任, 成为 “有理想、有本领、有担当” 的人才。

\section{1 教学现状}

当前, 国内外很多高校都为学生开设了专门的绿色化学课程, 介绍绿色化学的原理、方法和应 用等情况 ${ }^{[2-4]}$ 。最初的类似于绿色化学的课程是基于可持续发展理念发展起来的, 早在1992年就已出 现 “化学和可持续发展” (Chemistry and Sustainability (C\&S)) 的类似课程 ${ }^{[5]}$ 。美国 Scranton大学、澳大 利亚的Monash大学都早在2000年就开设了绿色化学课程。美国Massachusetts大学在2001年开始设立 绿色化学博士学位 ${ }^{[6]}$ 。在我国, “绿色化学” 作为一门独立的新课于1998年在中国科学技术大学顺利 实施, 四川大学也从 2002 年就开设了绿色化学课程, 并建设成了国家级精品课程 ${ }^{[7]}$ 。国外的绿色化 学常与可持续发展理念相融合, 发展出了绿色可持续发展化学教育课程(GSCE) ${ }^{[8]}$ 。他们认为GSCE 可以为化学工业或决策者培养富有责任感的公民, 并将可持续发展理念和生活方式传递给公众。我 国的绿色化学课程大部分也致力于帮助学生深刻理解绿色化学的涵义、目标、特点和内容, 转变学 生传统的化学观念, 认识到绿色化学在可持续发展中的重要作用, 通过系统的绿色化学知识的学习, 在绿色化学的基本原则的指导下, 将来能用绿色化学的思维方式来指导生产实践, 解决生产实际中 带来的污染问题 ${ }^{[9]}$ 。然而, 当前大学中开设的各类绿色化学课程的教学大部分以讲授各种绿色技术 与方法为主, 学生对绿色化学课程的学习态度缺乏动力和激情, 只注重于理论学习, 并未将绿色化 学知识与当前的祖国建设联系起来。

因此, 在绿色化学课程中实施思政教学, 对提高学生的社会责任感, 积极地将自己融入当前的 生态文明建设洪流中, 提高学生将理论应用于实际的绿色产品生产的能力都有重要的意义。

\section{2 绿色化学概论教学内容的课程思政元素}

绿色化学课程作为一门新兴课程, 不是一门独立的学科, 它是一种战略方针、一种指导思想、 一种研究政策。在我国生态文明建设的大背景下, 绿色化学课程无论在促进树立生态文明观方面还 是走绿色发展之路方面都应该能够发挥出更好的作用。经过两年的课程建设, 我校的绿色化学概论 课程每年吸引了 100 多人上课, 教育受众广泛。绿色化学课程蕴含丰富的思政元素, 在所选用的教材 《绿色化学原理与应用》 ${ }^{[10]}$ 中, 每一章内容都有融入思政教育的切入点。

\section{1 树立可持续发展的消费观和价值观}

绪论中主要介绍了人类当前面临的严重的环境污染问题和资源枯竭问题, 由此引出全球的可持 续发展战略。在此大背景下, 化学该怎么办? 环境和资源问题与每个人都息息相关, 每个人如果过 度消费都会对环境和资源造成破坏, 但是如果每个人都学会尊重自然、保护自然, 尽量节约资源, 秉持可持续发展的思想, 就能对环境保护做出很大贡献。因此在本章的讲解过程中, 通过播放图片 和视频等方式, 向学生展示环境破坏的恶果, 并展示我国十八大以来生态文明建设的成果和一些政 策法规, 如太湖沿岸生态环境的变迁, 实施垃圾分类前后垃圾填埋处理量的变化及垃圾分类回收的 情况, 让学生感受到可持续绿色发展才是我国建设社会主义现代化的必然之路, 每个人都应转变消 费观念, 提倡节约、环保、循环利用的生产和消费方式, 建立起新的道德和价值标准。而对于我们 
化学相关专业的学生, 如何才能在生态文明建设中更好地体现自己的人生价值? 通过认真学习绿色 化学的基本原理和方法, 掌握更多设计和制造绿色化学品的方法和技术, 改变传统化学品对环境和 人类造成巨大危害的状况, 用更加绿色安全的产品来推动社会文明的发展进步。

\section{2 脚踏实地地学习和工作}

第二章主要介绍了绿色化学的内涵、绿色化学与环境保护的差异、绿色化学的评价指标一一原 子经济性和绿色化学的任务等内容。绿色化学的目标是化学过程不产生污染, 是从源头上、根本上 减少或消除污染的化学。这个目标追求的是完美, 但也应该明白, 实现这个目标不是一蹴而就的, 而是需要逐步优化化学反应的每一个因素, 一步步地实现完全的绿色化。这也告诉学生们, 任何事 物并不会像想象的那么简单。我们要做的是坚定信念, 牢记绿色化学的原则和任务, 哪怕一次只能 实现一小部分的绿色化, 也能在数十次乃至数千次的绿色化改进中最终实现完美的绿色化。就如硝 基苯合成对苯二胺, 其原子利用率也是通过对催化剂的多次优化才达到最佳值。基于这个例子, 引申到我国的生态文明建设、脱贫攻坚战也是经历了很多的波折, 然而全国众多党员干部勇担重任、 迎难而上, 克服了一个又一个困难, 最终使我国走上健康的绿色发展之路, 基本实现了小康社会。 而学生只有脚踏实地地学习和工作, 才能实现自己的人生目标, 并在祖国建设中实现更高的人生价值。

\section{3 掌握更完备的知识体系}

第三章主要内容是毒理学分析及相关分子设计, 利用构效关系设计安全化学品。这里涉及的化 学品的毒性和毒理学基础以及构效关系都是传统的化学专业课程体系未涉及的内容。因此学生在这 方面的知识基础较为薄弱, 学习也缺乏兴趣。为了让学生意识到这些内容对绿色化学的重要性, 并让 他们具有更完备的绿色化学知识体系, 笔者通过查阅资料, 在授课内容中增加了毒理学知识, 如一 些常见化学品的毒性、产生毒性的机理和影响毒性的因素, 以及某些化学品结构特征与生物效能之 间的关系。某些内容以新闻视频的形式展示给学生, 以增加学生的学习兴趣和效果。

又如在向学生介绍细胞色素P450的性质和功能时, 通过查阅文献让学生了解细胞色素P450酶具 有独特的物理、化学、生物性质, 因此在药物代谢、激活、毒性降解等方面具有至关重要的意义。 不仅可以代谢多种脂肪酸、芳香烃、杀虫剂、除草剂、致癌物等有毒化学品, 还具有很强的催化能 力和催化化学反应的多样性, 以及立体和氧化位点的高度选择性而应用于有机合成、药物合成以及 合成生物学领域。因此有学者建议化学、生物学、医学、环境学等相关专业的学生和研究者都有必 要学习细胞色素P450的相关知识, 以便利用其不同的特性避免所设计的化学品产生代谢毒性, 而是 通过生物催化与合成化学融合造福人类。

\section{4 以更强的社会责任感去设计和使用更绿色的原料和产品}

第四章主要内容是设计可生物降解的化学品和对水生生物更加安全的化学品。曾经 “白色污染” 一词是我们耳熟能详的污染名词。“白色污染” 是人们对聚苯乙烯、聚丙烯、聚氯乙烯等塑料垃圾 污染环境的一种形象称谓。由于塑料垃圾产生量大, 被随意乱丢乱扔并且难于降解处理, 以致造成 严重的环境污染。解决这一问题的最有效方法就是用可生物降解的材料取代传统的塑料。通过在课 程中向学生展示塑料垃圾对生态环境破坏的图片和数据, 激励学生掌握设计可生物降解材料的原理 和方法, 并向公众宣传尽量减少使用传统的塑料制品, 或用可降解材料替代, 通过自己的努力设计 出更加安全的可降解材料, 减少 “白色污染” 的产生, 为我国的绿色发展之路扫除污染, 增添绿色。

\section{5 灵活应用各种绿色化学方法, 提高专业能力}

一个化学反应包含多个要素, 如原料、产品、反应路线、反应条件、反应器等。如图1所示, 要 实现绿色化学反应, 就需要对上述各个要素进行绿色化改进。绿色化学研究者只有掌握广博深厚的 专业知识, 才能灵活应用各种绿色化学方法, 实现化学反应的绿色化。作为化学专业的学生, 只有 掌握好专业基础知识, 并通过查阅资料和实验探究, 才能切实提高专业能力, 从而为绿色化学的发 展和社会的进步贡献力量。因此在课程中, 通过向学生展示如何针对某一要素查阅并总结文献, 设 计并指导相应的绿色化学实验, 促进学生扩大知识面, 灵活应用各种绿色化学方法, 提高实验探究 
能力。如对学生布置一个关于微型反应器的文献查阅作业, 让他们总结目前用于化学合成的微反应 器有哪些类型, 各有什么特点。同时教师设计一个关于 “玻璃微通道反应器的制备及光催化合成安 息香乙醚” 的绿色化学实验, 让学生在实验中感受到微反应所具有的微量、高效、高选择性、低能 耗的特点。

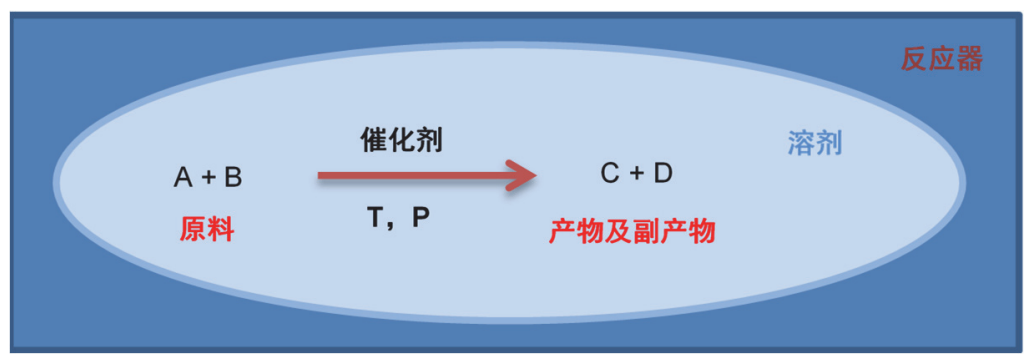

图1 化学反应的各要素

\section{3 思政教学方法}

绿色化学概论课程在我校是一门专业选修课, 如果采用单一的讲授形式向大家介绍绿色化学的 内容就会使课堂显得枯燥乏味, 使学生失去兴趣, 降低教学效果。除了采用插播与课程内容相关的 视频、开设绿色化学实验等教学手段来提高学生的学习兴趣和学习效果之外, 我们还尝试了多种形 式的活动, 如布置专题调查讨论、开展社会实践等, 使学生对绿色化学在国家、社会、经济的发展 中所起到的重要作用进行深入了解。

\section{1 专题调查和讨论}

绿色化学的原理和技术最终要应用到社会生产当中, 可持续发展的理念需要传播到社会每一个 人, 才能使我国的生态文明建设乃至全世界的可持续发展顺利地得以实现。但是对于书本中介绍的 这些绿色化学方法和技术到底有多少已被应用于实践当中呢? 我国的绿色化学技术发展到了何种程 度? 学生在绿色化学概论课程的学习过程中很容易产生这样一些疑问。为了解除学生的困惑, 以大 作业的形式让学生通过查阅资料, 分小组调查一个绿色化学相关的主题, 如当前中国突出的一些环 境问题、一些绿色化学实施较好的企业等, 以专题报告的形式在课堂上展示, 并进行小组间的相互 讨论和评价。通过该活动让学生对我国及世界各国的绿色化学技术应用情况有更深入的了解, 并引 导学生意识到自己所学的绿色化学知识完全可以有用武之地, 将来也可以在祖国的绿色发展中贡献 自己的力量。

开展绿色企业调查专题活动时, 要求学生从企业的经营理念、绿色化技术、社会效益、存在问 题等方面进行调查。现选取四组学生的调查结果列于表 1 。通过对绿色企业的调查和讲演活动, 使学 生对绿色化学技术在国内及国外企业中的应用情况有了深刻认识, 绿色化学知识不再局限于书本上, 而是在实际的生产和生活当中。绿色企业的一些经营理念和企业文化也告诉学生, 实现生态文明建 设和绿色发展, 需要勇于担责、追求卓越的精神和人与自然和谐共生的意识。

\section{2 开展社会实践}

绿色化学是与社会和生活联系非常紧密的一门课程, 因此也具有很强的实践性。可以利用周末 或暑期组织学生开展绿色化学宣传活动或绿色企业参观等社会实践活动。这样的社会实践活动笔者 已组织开展了两届。社区宣传的主题包括垃圾分类回收宣传和可降解材料的宣传。参观的绿色企业 包括义乌双童日用品有限公司和杭州天子岭垃圾填埋场。通过社区宣传活动, 让学生体会到我国的 居民垃圾分类意识还不够强, 分类工作也不够细致。作为化学专业的学生有责任向周围的民众宣传 垃圾分类回收的必要性和有利性, 有责任研究出更多可降解的、环境无害的绿色产品替代原来的有 害产品, 从而切实地为我国的生态文明建设做出贡献。此外, 在绿色企业参观中让学生体会到, 企 业的绿色理念不仅仅体现在技术和产品上, 更体现在营造人与自然和谐共生的厂区绿色环境。一个 
大学化 学 Univ. Chem. 2021, 36(3), 2010031 (5 of 5)

\begin{tabular}{|c|c|c|c|c|}
\hline & & 表1 绿色企业调查内容 & & \\
\hline 绿色企业 & 绿色技术 & 绿色产品 & 经营理念 & 存在问题 \\
\hline 北京三聚环保 & 1. 超级悬浮床加氢技术 & 1. 加氢催化剂 & 对环境的负面影响降 & 1. 产品结构单一, 绿色技 \\
\hline 新材料股份有 & 2. 低能耗高效钉基合成氨技术 & 2. 氧化锌、高硫容脱硫剂 & 到最小 & 术尚未转化为产品 \\
\hline \multirow[t]{2}{*}{ 限公司 } & 3. 低温催化燃烧技术 & & & 2. 生物质柴油成本高 \\
\hline & 4. 生物质资源综合利用技术 & & & \\
\hline 河北协同环保 & 1. 聚天冬氨酸及应用 & 1. 聚天冬氨酸 & 做绿色化学的引导者, & 1. 资金不足，亏损问题尚 \\
\hline 科技股份有限 & 2. 母体丁烯二酸与土壤修复 & 2. 工业废水第三方治理 & 成就品质生活 & 未解决 \\
\hline \multirow[t]{2}{*}{ 公司 } & 3. 亚氨基二琥珀酸及应用 & 3. 生物发酵水处理和服务 & & 2. 技术部门与生产与销 \\
\hline & & & & 售部门之间的接口问题 \\
\hline 常州亿晶光电 & 1. 光伏发电技术 & 1. 太阳能电池片及组件 & 成为具有核心竞争力 & 1. 能量转换效率低 \\
\hline \multirow[t]{3}{*}{ 科技有限公司 } & 2. 高纯度单晶硅制造技术 & 2. 蓝宝石晶体材料 & 的、创造幸福生活、服 & 2. 系统成本高 \\
\hline & 3. 太阳能、风能、柴油发电互补 & 3. 单晶硅、多晶硅及硅晶炉 & 务人性化、经营国际化 & 3. 晶体硅电池的制造过 \\
\hline & 发电系统工程 & & 的领军企业 & 程高污染、高能耗 \\
\hline 深圳绿色动力 & 1. 二噁英的智能防控技术 & BOT 模式经营生活垃圾焚烧发 & 化腐朽, 为能源——创 & 政府对企业的财政与政策 \\
\hline 环境工程有限 & 2. 垃圾焚烧发电烟气净化处理 & 电业务 & 造美好生活环境, 为人 & 支持力度不足 \\
\hline \multirow[t]{2}{*}{ 公司 } & 技术 & & 与自然和谐共生贡献 & \\
\hline & & & 力量 & \\
\hline
\end{tabular}

真正的绿色企业是将绿色理念渗入每一个 “毛孔”，而置身其中的人自然被浸润成 “通体绿色”， 从思想到行动。

\section{4 结语}

在两年的教学过程中, 通过对上述各项改革方案进行实践, 获得了较好的教学效果。首先学生 对该课程的兴趣大大增加, 选课的人数也大大增加。根据反馈信息, 学生选这门课不是纯粹为了修 满学分, 而是因为课程 “比较有趣”。其次, 学生通过学习, 极大地加深了对绿色化学原理和方法的 理解和掌握, 也增强了他们的社会责任感, 改变了他们对化学的情感态度与价值观。有些同学能主 动将对绿色化学的学习与当前的生态文明建设, 践行 “绿水青山就是金山银山” 联系起来, 对自己 能用所学知识为祖国的建设贡献力量而倍感自信。此外, 通过组织学生的社会实践活动, 让学生加 深对社会现状的认识, 开阔了眼界, 增强了他们发现问题、解决问题的能力, 也提高了学生对社会 的适应能力。同时，这些社会实践活动也赢得了一些荣誉，帮助学生将来更好地就业。

总之, 绿色化学的思政改革与社会现实和国家的生态文明建设的切合点很多, 因此可以形式多 样, 灵活选择, 而效果也是显而易见的。

\section{参 考 文 献}

[1] 新华网. “两山论”引领绿色发展之路. [2017-08-02]. http://www.xinhuanet.com/comments/2018-05/21/c_1122862942.htm

[2] 沈玉龙, 关俊霞, 刘立华, 曹文华. 大学化学, 2011, 26 (6), 19.

[3] 张变香, 方莉, 魏学红. 化工高等教育, 2010, No. 6, 27.

[4] 王勇, 左霞, 吉琳, 周荫庄. 首都师范大学学报(自然科学版), 2011, No. 32, 74 .

[5] Collins, T. J. J. Clean. Prod. 2017, 140, 93.

[6] 沈玉龙, 王克诚. 环境教育, 2005, No. 1, 63.

[7] 刘莲云, 颜鲁婷, 戴春爱, 张辉. 化学教育, 2007, No. 11, 16.

[8] Eilks, I.; Zuin, V. G. Curr. Opin. Green Sustain. Chem. 2018, 13, A4.

[9] 翟翠萍, 刘学军. 化学工程与装备, 2013, No. 4, 195.

[10] 胡常伟, 李贤均. 绿色化学原理和应用. 北京: 中国石化出版社, 2007. 